proceeded to deduce them from the details of the act of measurement-the necessity for four entities such as the two ends of the measuring scale and those of the rod to be measured, etc. He sought to meet the difficulty of biology not by forcing it into the metrical scheme but by denying that it was science and classifying it with theology.

I agree that the distinction between the metrical and the non-metrical has led many people to place science in a perspective; I do not agree that it is the right perspective, and I still think that error on such a matter is tragical, whether it is an error that conforms to our prejudices or not.

University College,

Herbert Dingle

London, W.C.1.

\section{A Rapid Method of Analysis for Certain Surface-Active Agents}

WE note with interest a letter by S. R. Epton ${ }^{1}$ which describes a partition end-point method for estimation of surface-active agents in solution. We can confirm that such a method gives accurate and reliable results, since a method similar in essentials has been in use in these laboratories for the last two years and was described by one of us in a lecture to students of the Manchester College of Technology in February of this year.

A complete description of our method, which embodies an improvement over the methylene blue method, was submitted for publication to a chemical journal on September 3, 1947.

$$
\begin{aligned}
& \text { T. Barr } \\
& \text { J. OLIVER } \\
& \text { W. V. StTUBbINGS }
\end{aligned}
$$

Dyehouse Laboratories and

Analytical Laboratories,

Imperial Chemical Industries, Ltd., Hexagon House, Manchester 9.

${ }^{1}$ Nature, 160, 795 (1947).

\section{"Structure of Spectral Lines"}

In Nature of August 23, p. 244, Dr. D. A. Jackson reviews my recent book on "High-Resolution Spectroscopy" (Methuen, 1947). After considerable hesitation and with much reluctance, I feel compelled to comment on several misrepresentations made by Dr. Jackson. That he appears to dislike my method of historical approach is a matter of personal taste with which I do not quarrel, but I cannot allow incorrect assessments of my views to pass unchallenged.

With regard to light sources, his failure to appre. ciate the wide range and applicability of the various hollow cathode sources I have described is fairly widespread, and indeed this common attitude was a prime reason for their inclusion. By far the biggest volume of published work in hyperfine structure has been made with the different varieties of hollow cathode source.

With regard to the atomic beam as a source, Dr. Jackson quotes me as saying (p. 82), "it is therefore very easy to miss weak components". My complete statement reads, "it is therefore very easy to miss weak components in a structure if the beam is not dense enough" (italics added). I think, too, in the circumstances, that the six lines of the review referring to the detection of weak components in potassium (made by Drs. Jackson and Kuhn) could well have been spared, since I give these very details on the following page, with due apportioning of credit.

What astonishes me is the accusation that I understate the superiority of the Fabry-Perot etalon, and I can only conclude that Dr. Jackson has not read my sentence on p. 89: "The Fabry-Perot interferometer has therefore greater power than any of the other instruments in general use". Needless to say, my treatment makes this so obvious that I am quite dumbfounded at Dr. Jackson's failure to appreciate my outlook. I devote 143 pages to instruments: 25 pages to the echelon, 38 pages to the Lummer plate and 80 pages to the Fabry-Perot etalon. If Dr. Jackson does not realize that fact, surely he saw the clear table on p. 88, where I place the Fabry-Perot at the head of the instruments listed in order of practical importance. I feel strongly that misrepresentation in this matter is highly un. desirable in the interests of spectroscopy.

Dr. Jackson makes a good deal of play with the reflectivity measurements I have quoted (be it noted, from other workers). I heartily concur when he writes that but few and contradictory measurements are available, but he cannot have it both ways, for he then proceeds to remark : "If the curve had been drawn correctly ..." May I ask on whose authority, and to which 'correct' curve does he refer? Is it perhaps to some unpublished figures of his own, since he is able to quote figures? Dr. Jackson prefers to select his mirrors with a photo-electric meter (which, incidentally, only measures the absorption, and not the rellectivity, an issue he side-steps). but I still prefer to use 'considered judgment' in my own experiments.

Again, with regard to reflectivity, Dr. Jackson states that sputtering is obsolete; but I have taken pains to show that some quite exceptionally good figures have been reported for sputtering methods, and this should be re-examined. However, I state explicitly on p. 113: "The superiority of the evaporated film over the sputtered film is evident". I personally also only use evaporation.

Finally, Dr. Jackson dislikes mountings of the reflexion echelon other than that he himself uses, and he argues that my discussion of the limitations of his mounting is irrelevant. Surely one might be a little less partisan, and in any case a text-book writer must be.

\section{Royal Holloway College, Englefield Green, Surrey.}

\section{S. TOLANSKY}

The criticism which I made about Prof. Tolansky's description of the hollow cathode was that it is "concerned too much with complicated and obsolete forms". I do not fail to appreciate the work which has been done with this light-source in its most important forms, but I criticize the relative amount of space devoted by Prof. Tolansky to obsolete and little-used varieties.

With regard to the atomic beam in absorption, although it is established that this method permits the observation of lines too weak to be detected in emission, Prof. Tolansky does not mention this advantage, but deals at some length with the ease with which weak components are missed if the density 